\title{
Multiplex PCR-Based Next-Generation Sequencing and Global Diversity of Seoul Virus in Humans and Rats
}

\author{
Won-Keun Kim, ${ }^{1}$ Jin Sun No, ${ }^{1}$ Seung-Ho Lee, Dong Hyun Song, Daesang Lee, \\ Jeong-Ah Kim, Se Hun Gu, Sunhye Park, Seong Tae Jeong, Heung-Chul Kim, \\ Terry A. Klein, Michael R. Wiley, Gustavo Palacios, Jin-Won Song
}

Seoul virus (SEOV) poses a worldwide public health threat. This virus, which is harbored by Rattus norvegicus and $R$. rattus rats, is the causative agent of hemorrhagic fever with renal syndrome (HFRS) in humans, which has been reported in Asia, Europe, the Americas, and Africa. Defining SEOV genome sequences plays a critical role in development of preventive and therapeutic strategies against the unique worldwide hantavirus. We applied multiplex PCR-based next-generation sequencing to obtain SEOV genome sequences from clinical and reservoir host specimens. Epidemiologic surveillance of $R$. norvegicus rats in South Korea during 2000-2016 demonstrated that the serologic prevalence of enzootic SEOV infections was not significant on the basis of sex, weight (age), and season. Viral loads of SEOV in rats showed wide dissemination in tissues and dynamic circulation among populations. Phylogenetic analyses showed the global diversity of SEOV and possible genomic configuration of genetic exchanges.

$\mathrm{H}$ antaviruses (order Bunyavirales, family Hantaviridae, genus Orthohantavirus) pose a worldwide public health threat and are the causative agents of hemorrhagic fever with renal syndrome (HFRS) in Eurasia and hantavirus pulmonary syndrome in the Americas (1). HFRS is caused mainly by Old World hantaviruses, such as Hantaan virus (HTNV), Seoul virus (SEOV), Dobrava-Belgrade virus, and Puumala virus, that are transmitted to humans by inhalation of dust contaminated with rodent excreta (saliva, urine, and feces) or bite by an infected rodent.

Author affiliations: Korea University, Seoul, South Korea

(W.-K. Kim, J.S. No, S.-H. Lee, J.-A. Kim, J.-W. Song); Agency for Defense Development, Daejeon, South Korea (D.H. Song, D. Lee, S.H. Gu, S. Park, S.T. Jeong); 65th Medical Brigade/Medical Department Activity-Korea, Seoul (H.-C. Kim, T.A. Klein); US Army Medical Research Institute of Infectious Disease, Fort Detrick, Maryland, USA (M.R. Wiley, G. Palacios)
Annually, 150,000 cases of HFRS are reported (case-fatality rate range $<1 \%-15 \%$ ) (2). Clinical signs and symptoms include headache, myalgia, abdominal and back pain, nausea, vomiting, diarrhea, proteinuria, thrombocytopenia, hemorrhage, and renal failure (3). The typical disease course consists of 5 phases: febrile, hypotensive, oliguric, diuretic, and convalescent: the phases vary in length from several hours to several days. A difficulty in diagnosis is the extensive incubation period from the time of exposure to the onset of symptoms, which might be as long as 50 days. There are no effective vaccines or antiviral agents against hantavirus infection.

SEOV has a negative-sense, single-stranded, tripartite RNA genome (4). The large (L) segment encodes an RNAdependent RNA polymerase, the medium (M) segment encodes 2 membrane glycoproteins ( $\mathrm{Gn}$ and $\mathrm{Gc}$ ), and the small (S) segment encodes a nucleoprotein. Brown rats (Rattus norvegicus) and black rats ( $R$. rattus) are the primary reservoir hosts of SEOV and have a worldwide distribution $(5,6)$.

SEOV infections have been reported in Asia, Europe, the Americas, and Africa (7-12). HFRS caused by SEOV is responsible for $25 \%$ of clinical cases and is a mild form with a case-fatality rate of $<1 \%$ in Asia (13). Recently, an outbreak of SEOV-induced HFRS was reported in the United Kingdom among rat owners, breeders, and distributors of the pet animal market (14). In the United States, outbreaks of SEOV infections occurred in 11 states in 2017; there were 17 confirmed SEOV-infected patients $(15,16)$. SEOV was identified in New York, New York, and is considered an urban public health threat (17).

Whole-genome sequencing of SEOV is a prerequisite for tracking SEOV infections and evaluating disease risks for development and implementation of preventive and therapeutic strategies. Acquisition of viral genome sequences plays a critical role in surveillance, identification, and risk mitigation of outbreaks of virus infection (18). Nextgeneration sequencing (NGS) is a potent tool for defining

${ }^{1}$ These authors contributed equally to this article. 
virus genome sequences. However, an obstacle for obtaining virus genomic information is ultra-low virus RNA loads in the clinical specimens. To enrich the low amount of viral RNA, we developed a multiplex PCR-based NGS that showed high coverage of HTNV genome sequences from HFRS patients (19).

In this study, we collected 1,269 $R$. norvegicus rats in an urban HFRS-endemic area in South Korea during 2000-2016. We report a robust strategy for whole-genome sequencing of SEOV and provide useful insights into epidemiologic characteristics and phylogeographic diversity of a unique worldwide hantavirus.

\section{Materials and Methods}

\section{Ethics}

Human samples were provided after informed consent was obtained. The study was approved and conducted in accordance with ethics guidelines for the Korea University Institutional Animal Care and Use Committee. Live trapping of rats at US military training sites and installations was approved by US Forces Korea in accordance with regulation 40-1 (Prevention, Surveillance, and Treatment of Hemorrhagic Fever with Renal Syndrome). Rats were humanely killed by cardiac puncture, and tissues were collected under isoflurane anesthesia in accordance with procedures approved by Korea University Institutional Animal Care and Use Committee protocol \#2010-212.

\section{Sample Collection}

We tested retrospective HFRS patient serum samples obtained from the Korea Bank for Pathogenic Viruses (Seoul, South Korea). We collected $R$. norvegicus rats during 2000-2016 by using collapsible live-capture traps (Tomahawk Live Trap Co., Hazelhurst, WI, USA, and H.B. Sherman, Tallahassee, FL, USA). Traps were set at intervals of 1-2 $m$ and examined early the next morning over a 1-2-day period at US Army training sites. For the US Army Garrison in Seoul, we used baited live capture traps (Tomahawk Live Trap Co.) or glue boards. Captured rats were submitted to the 5th Medical Detachment/Medical Command Activity-Korea, US Army Garrison (Yongsan, Seoul), and then transported to the College of Medicine, Korea University (Seoul), where they were held in a Biosafety Level 3 laboratory until processing. Live rats were humanely killed by cardiac puncture under isoflurane anesthesia and identified to species by using morphologic criteria and PCR, when required. Serum, lung, spleen, kidney, and liver tissues were collected aseptically and frozen at $-70^{\circ} \mathrm{C}$ until used.

\section{Indirect Immunofluorescence Antibody Test}

We used an indirect immunofluorescence antibody (IFA) test for serum samples from HFRS patients and live rats.
We initially diluted samples $1: 32$ in phosphate-buffered saline and then tested them for IgG against SEOV. We applied diluted serum samples to slides containing SEOV-infected Vero E6 cells fixed with acetone and incubated wells at $37^{\circ} \mathrm{C}$ for $30 \mathrm{~min}$. The slides were washed, fluorescein isothiocyanate-conjugated goat antibody to human and rat IgG (ICN Pharmaceuticals, Laval, Quebec, Canada) was added, and slides were incubated at $37^{\circ} \mathrm{C}$ for $30 \mathrm{~min}$. We then washed the slides again and examined them for virusspecific fluorescence by using a fluorescent microscope (Axio Scope; Zeiss, Berlin, Germany).

\section{Real-Time Quantitative PCR}

We performed real-time quantitative PCR (qPCR) for total RNA by using the high-capacity RNA-to-cDNA Kit (Applied Biosystems, Carlsbad, CA, USA) in a $10-\mu \mathrm{L}$ reaction mixture containing $1 \mu \mathrm{g}$ of total RNA. We used an SYBR Green PCR Master Mix (Applied Biosystems) in a StepOne Real-Time PCR System (Applied Biosystems). We performed reactions at $95^{\circ} \mathrm{C}$ for $10 \mathrm{~min}$, followed by 45 cycles at $95^{\circ} \mathrm{C}$ for $15 \mathrm{~s}$, and then 1 cycle at $60^{\circ} \mathrm{C}$ for $1 \mathrm{~min}$. Primer sequences specific for SEOV S segments were SEOV-S719F: 5'-TGGCACTAGCAAAAGACTGG-3' and SEOV-S814R: 5'-CAGATAAACTCCCAGCAATAGGA-3'.

\section{Reverse Transcription and Rapid Amplification of CDNA Ends PCR}

We extracted total RNA from serum or lung tissues of seropositive samples by using TRI Reagent Solution (Ambion Inc., Austin, TX, USA). We synthesized cDNA by using the High Capacity RNA-to-cDNA Kit (Applied Biosystems) and random hexamer or OSM55 (5'-TAGTAGTAGACTCC-3'). For initial identification, we used oligonucleotide primers for SEOV L segment as described (20). To obtain the $3^{\prime}$ and $5^{\prime}$ termini genome sequences of SEOV, we performed rapid amplification of cDNA ends (RACE) PCR by using a 3'-Full RACE Core Set and a 5'-Full RACE Core Set (Takara Bio Inc., Kusatsu, Shiga, Japan), according to the manufacturer's specifications. We purified PCR products by using the LaboPass PCR Purification Kit (Cosmo Genetech, Seoul, South Korea). We performed sequencing in both directions of each PCR product by using the BigDye Terminator v3.1 Cycle Sequencing Kit (Applied Biosystems) on an automated sequencer (Applied Biosystems).

\section{Multiplex PCR-Based NGS}

We designed multiplex PCR primers for SEOV L, M, and $\mathrm{S}$ segments and amplified cDNA by using primers (online Technical Appendix 1, https://wwwnc.cdc.gov/EID/ article/24/2/17-1216-Techapp1.xlsx) and primer mixtures and Solg 2× Uh-Taq PCR Smart Mix (Solgent, Daejeon, South Korea), according to the manufacturer's instructions. 
We performed the first and second enrichments in a $25-\mu \mathrm{L}$ reaction mixture containing $12.5 \mu \mathrm{L}$ of $2 \times$ Uh pre-mix, 1 $\mu \mathrm{L}$ of cDNA template, $10 \mu \mathrm{L}$ of primer mixture, and 1.5 $\mu \mathrm{L}$ of distilled water. Initial denaturation was at $95^{\circ} \mathrm{C}$ for $15 \mathrm{~min}$, followed by 40 cycles or 25 cycles at $95^{\circ} \mathrm{C}$ for 20 $\mathrm{s}, 50^{\circ} \mathrm{C}$ for $40 \mathrm{~s}$, and $72^{\circ} \mathrm{C}$ for $1 \mathrm{~min}$, and a final elongation at $72^{\circ} \mathrm{C}$ for $3 \mathrm{~min}$.

We prepared multiplex PCR products by using the TruSeq Nano DNA LT Sample Preparation Kit (Illumina, San Diego, CA, USA) according to the manufacturer's instructions. We mechanically sheared samples by using an M220 focused ultrasonicator (Covaris, Woburn, MA, USA). The cDNA amplicon was size-selected, A-tailed, ligated with indexes and adaptors, and enriched. We sequenced libraries by using the MiSeq benchtop sequencer (Illumina) with $2 \times 150 \mathrm{bp}$ and a MiSeq reagent V2 (Illumina). We imported and analyzed Illumina FASTQ files by using EDGE (21).

\section{Phylogenetic Analysis}

We aligned and edited virus genome sequences by using the multiple sequence alignment with high accuracy and high throughput algorithm (22). We generated phylogenetic trees by using the maximum-likelihood method in MEGA version 6.0 (23) and models for analysis according to the best fit substitution model (TN93 + gamma + invariate for L segments, general time reversible + gamma + invariant for $\mathrm{M}$ segments, and $\mathrm{T} 92+$ gamma for $\mathrm{S}$ segments). We assessed support for topologies by bootstrapping for 1,000 iterations. The prototype strain used, SEOV 80-39, was isolated from $R$. norvegicus rats captured in Seoul in 1980.

\section{Results}

\section{Retrospective Analysis of HFRS Patient Specimens}

We found that specimens collected in 2002 from 6 HFRS patients were positive for SEOV by ELISA (J.-W. Song and $\mathrm{H}$. Kariwa, unpub. data). We confirmed that the HFRS specimens were serologically positive for SEOV by IFA (Table 1). Titers of SEOV-specific antibody ranged from 1:128 to $1: 4,096$. Reverse transcription PCR detected the partial sequence of L segment (nt 2946-3335) from 2 HFRS patients (Hu02-180 and Hu02-258).

\section{Epidemiologic Surveillance of $\boldsymbol{R}$. norvegicus Rats}

We collected 1,269 $R$. norvegicus rats in urban HFRSendemic areas in South Korea, including the city of Seoul $(1,226 / 1,269)$ and Gyeonggi $(40 / 1,269)$, Gangwon $(1 / 1,269)$, and Jeollanam $(2 / 1,269)$ Provinces (Table 2). A total of 76 $(6.2 \%)$ of 1,226 rats collected in Seoul were serologically positive for SEOV. However, we found IgG against SEOV in only $1(2.3 \%)$ of 43 rats collected from the other areas, including Gyeonggi, Gangwon, and Jeollanam Provinces. We detected SEOV RNA in 13 (16.9\%) of 77 seropositive $R$. norvegicus rats. Serologic prevalence of SEOV in male rats $(7.5 \%, 43 / 576)$ was not significantly different from that in female rats $(5.0 \%, 34 / 684)\left(\mathrm{p}=0.0763\right.$ by $\chi^{2}$ test $)$. Serologic prevalence of SEOV in rats by weight (age) was $6.1 \%(21 / 342)$ in those weighing $\leq 50 \mathrm{~g}, 5.9 \%(22 / 374)$ in those weighing $51-100 \mathrm{~g}, 5.8 \%$ (30/521) in those weighing $101-200 \mathrm{~g}$, and $13.8 \%(4 / 29)$ in those weighing $201-300 \mathrm{~g}$. Seasonal prevalence of SEOV infection in rats was $5.8 \%$ (11 of 190) in spring (March-May), 4.4\% (19/433) in summer (June-August), 6.4\% (27/420) in fall (September-November), and 10.0\% (19/190) in winter (December-February).

\section{SEOV RNA Loads in Tissues from Seropositive $R$. norvegicus Rats}

To measure viral load of SEOV RNA in $R$. norvegicus rats, we performed real-time qPCR for seropositive samples from lungs, livers, kidneys, and spleens (Figure 1). Viral load for SEOV showed ranges from tissues of 5 rats (Rn02-15, Rn10134, Rn10-145, Rn11-44, and Rn11-53) that were positive by serologic and molecular screening (IFA+ PCR+). Rat Rn10-145 showed the highest amount of SEOV RNA in all tissues, followed by rats Rn02-15 and Rn10-134. Rat Rn1144 showed the highest amount of SEOV RNA in all tissues except liver. Rat Rn11-53 showed the highest amount of SEOV RNA load in lung tissues, but virus RNA was not detectable in liver, kidney, and spleen tissues.

\section{Multiplex PCR-Based NGS for Retrospective HFRS Patient and $R$. norvegicus Rat Specimens}

We determined viral loads for HFRS patient specimens by using real-time $\mathrm{qPCR}$. Cycle threshold $\left(\mathrm{C}_{\mathrm{t}}\right)$ values ranged from 27.5 to 36.8 (Table 3). To perform multiplex PCR-based NGS for SEOV, we designed multiplex PCR primers to amplify

\begin{tabular}{|c|c|c|c|c|}
\hline Sample & Onset date & Collection date & IFA titer† & $\begin{array}{c}\text { Reverse transcription } \\
\text { quantitative PCR result }\end{array}$ \\
\hline SEOV Hu02-112 & Unknown & Unknown & $1: 128$ & - \\
\hline SEOV Hu02-180 & 2002 Feb 9 & 2002 Feb 15 & $1: 1,024$ & + \\
\hline SEOV Hu02-258 & 2002 Feb 28 & 2002 Mar 7 & $1: 4,096$ & + \\
\hline SEOV Hu02-294 & Unknown & Unknown & $1: 4,096$ & - \\
\hline SEOV Hu02-529 & 2002 May 8 & 2002 May 13 & $1: 2,048$ & - \\
\hline SEOV Hu02-668 & 2002 May 30 & 2002 Jun 18 & $1: 128$ & - \\
\hline
\end{tabular}


Table 2. Serologic and molecular prevalence of SEOV in Rattus norvegicus rats, by metropolitan area/province, sex, weight, and season, South Korea, 2000-2016*

\begin{tabular}{|c|c|c|c|}
\hline Characteristic & No. rats & $\begin{array}{c}\text { Prevalence of IgG against SEOV, } \\
\text { no. positive/no. tested (\%) }\end{array}$ & SEOV RNA, no. positive/no. tested (\%) \\
\hline \multicolumn{4}{|l|}{ Region, $\mathrm{n}=1,269$} \\
\hline Seoul & 1,226 & $76 / 1,226(6.2)$ & $13 / 76(17.1 \%)$ \\
\hline Gyeonggi Province & 40 & $1 / 40(2.5)$ & $0 / 1$ \\
\hline Gangwon Province & 1 & $0 / 1(0)$ & ND \\
\hline Jeollanam Province & 2 & $0 / 2(0)$ & ND \\
\hline \multicolumn{4}{|l|}{ Sex, $n=1,269$} \\
\hline M & 576 & 43/576 (7.5) & 9/43 (21.0) \\
\hline $\mathrm{F}$ & 684 & $34 / 684(5.0)$ & $4 / 34(11.8)$ \\
\hline Unknown & 9 & $0 / 9(0)$ & $0 / 9(0)$ \\
\hline \multicolumn{4}{|l|}{ Weight, $\mathrm{g}, \mathrm{n}=1,269$} \\
\hline$\leq 50$ & 342 & 21/342 (6.1) & $2 / 21(9.5)$ \\
\hline$\overline{5} 1-100$ & 374 & $22 / 374(5.9)$ & $3 / 22(13.6)$ \\
\hline $101-200$ & 521 & $30 / 521(5.8)$ & 7/30 (23.3) \\
\hline $201-300$ & 29 & 4/29 (13.8) & $1 / 4(25.0)$ \\
\hline Unknown & 3 & $0 / 3(0)$ & ND \\
\hline \multicolumn{4}{|l|}{ Season, $n=1,269$} \\
\hline Spring, Mar-May & 190 & 11/190 (5.8) & 0/11 (0) \\
\hline Summer, Jun-Aug & 433 & $19 / 433(4.4)$ & 2/19 (10.5) \\
\hline Fall, Sep-Nov & 420 & $27 / 420(6.4)$ & $6 / 27(22.2)$ \\
\hline Winter, Dec-Feb & 190 & 19/190 (10.0) & $5 / 19(26.3)$ \\
\hline Unknown & 36 & 1/36 (2.8) & $0 / 1(0)$ \\
\hline
\end{tabular}

every 150 -bp sequence for the entire SEOV tripartite genome. We recovered genomic sequences of SEOV from 6 SEOV-positive patient samples. We sequenced human sample $\mathrm{Hu} 02-258$, which showed the highest viral load (lowest $\mathrm{C}_{\mathrm{t}}$ value), for $99.6 \%$ of the $\mathrm{L}$ segment, $99.7 \%$ of the M segment, and $91.6 \%$ of the $\mathrm{S}$ segment. Recovery rates for SEOV genomic sequences from samples Hu02-180 and Hu02-529 showed a correlation with viral loads. Samples Hu02-112, Hu02-294, and Hu02-668 showed high recovery rates of SEOV S and M segments despite lower viral loads (highest $\mathrm{C}_{\mathrm{t}}$ values). However, the $\mathrm{L}$ segment showed relatively low coverages $(85.0 \%$ for $\mathrm{Hu} 02-180,68.2 \%$ for $\mathrm{Hu} 02-294$, and $72.7 \%$ for $\mathrm{Hu} 02-668)$.

Using total RNA extracted from rat lung tissues, we determined viral loads by using real-time $q P C R$. $\mathrm{C}_{t}$ values ranged from 16.1 to 27.6. We applied multiplex PCR- based NGS for whole-genome sequencing of 4 SEOV strains in the IFA + PCR + rats captured in South Korea during 2000-2016. Coverage of genomic sequences of SEOV was $99.1 \%-99.7 \%$ for $\mathrm{L}$ segments, $99.2 \%-99.7 \%$ for $\mathrm{M}$ segments, and $98.3 \%-99.4 \%$ for $\mathrm{S}$ segments. We observed a correlation between $\mathrm{C}_{\mathrm{t}}$ values and multiplex PCR-based NGS coverages (online Technical Appendix 2, https:// wwwnc.cdc.gov/EID/article/24/2/17-1216-Techapp2. pdf). Whole-genome sequences from Rn10-134, Rn10145, Rn11-44, and Rn11-53 were obtained with termini sequences of $3^{\prime}$ and $5^{\prime}$ ends. SEOV sequences were deposited in GenBank (accession nos. MF149938-MF149957).

\section{Global Diversity of SEOV}

We generated phylogenetic trees by using nearly complete genome sequences of SEOV and the maximum-likelihood

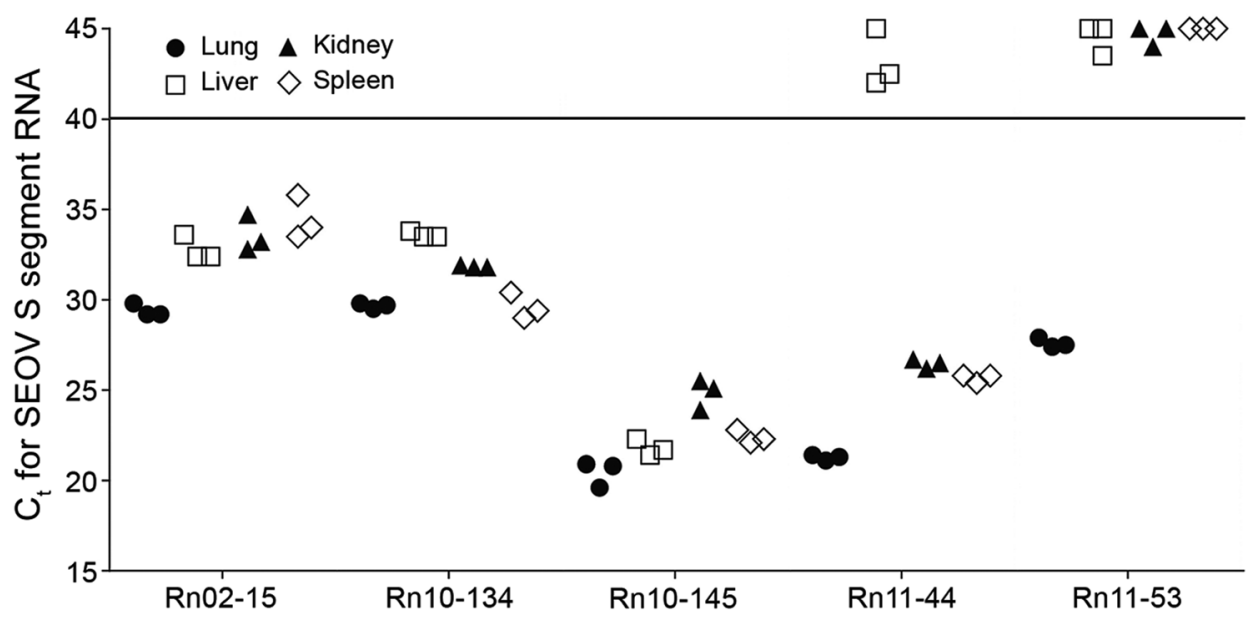

Figure 1. Measurement of SEOV RNA loads in different tissues of Rattus norvegicus rats, South Korea, 2000-2016. C values were determined for SEOV small segment RNA in lung, liver, kidney, and spleen tissues obtained from 5 rats positive for SEOV IgG and SEOV RNA. Solid horizontal line indicates assay cutoff value. $\mathrm{C}_{\mathrm{t}}$, cycle threshold; $S$, small; SEOV, Seoul virus. 


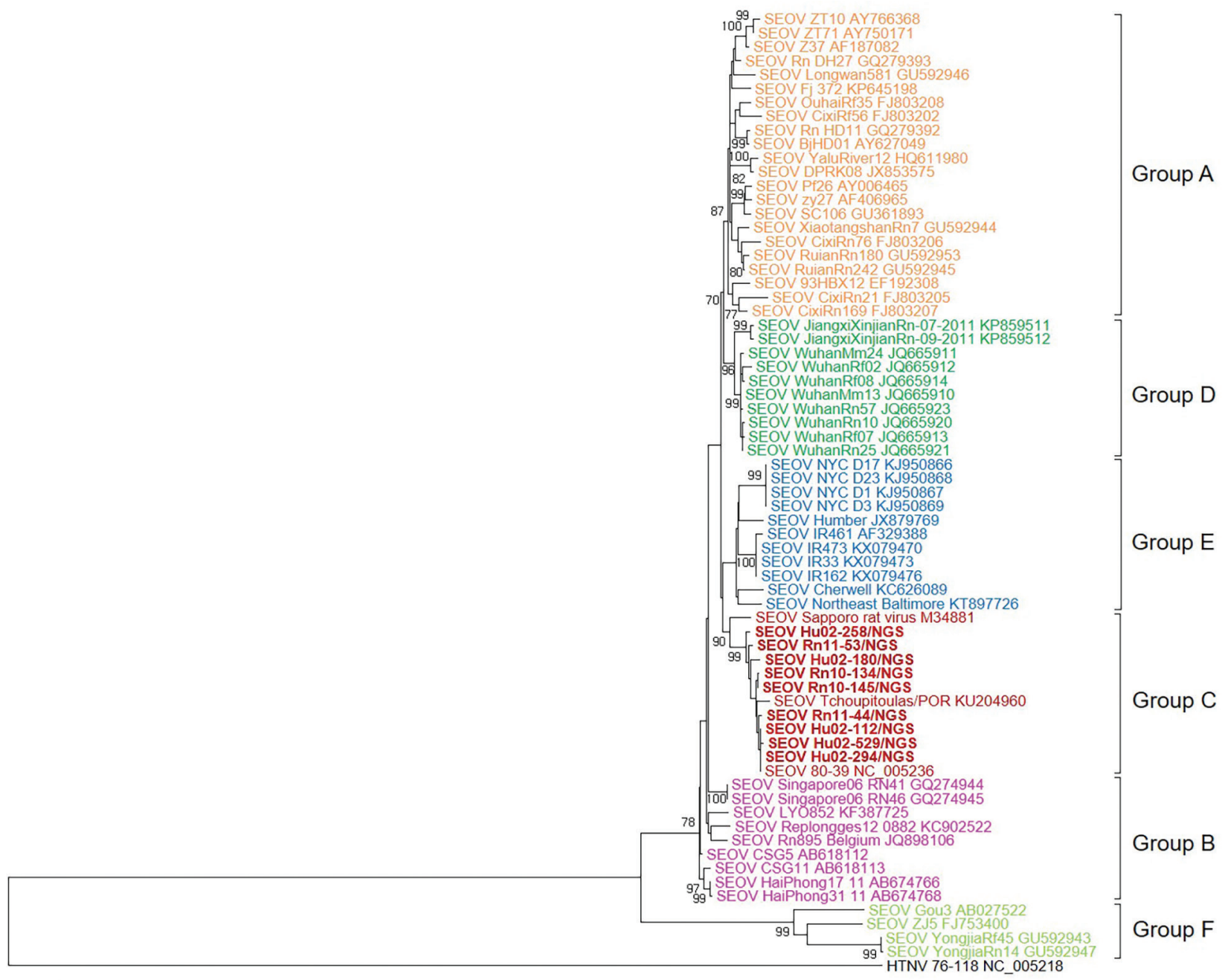

0.1

Figure 2. Phylogenetic analysis of SEOV small RNA segments, South Korea, 2000-2016, and reference strains. A phylogenetic tree was generated by using the maximum-likelihood method with the T92 + gamma distribution model of evolution and alignment of small RNA segment sequences (nt 193-1332) of SEOV strains. Colored groups indicate the areas where SEOV strains were identified: group A, northeastern and southeastern China and North Korea; group B, Europe (France and Belgium) and Southeast Asia (Vietnam and Singapore); group C, South Korea, Japan, and the United States; group D, southeastern China; group E, United Kingdom and the United States; group F, mountainous areas in southeastern China. Bold red indicates SEOV strains sequenced in this study. Topologies were evaluated by bootstrap analyses of 1,000 iterations. Numbers along branches are bootstrap values. GenBank accession numbers are provided. Scale bar indicates nucleotide substitutions per site. SEOV, Seoul virus.

railways and through seaports) (24). The close genetic relationship of SEOV in South Korea and Japan was probably caused by geographic distance and historical activities (e.g., commerce and occupation by Japanese forces). The genetic lineage containing strains from Southeast Asia and France might have originated during colonization or on trade routes that extended distribution of SEOV-infected rats (25). Recently, SEOV outbreaks have been reported in the United Kingdom and United States. Clinical cases showed that SEOV infections were identified among pet owners, breeders, and distributors (26). The genetic relationship of SEOV between counties probably reflects movement of rats associated with the animal pet market.

The prevalence of hantaviruses (e.g., HTNV and Imjin virus [MJNV]) in natural reservoir hosts has showed sexand weight (age)-specific differences $(27,28)$. However, in our study, the incidence of SEOV in $R$. norvegicus rats was not dependent on sex and weight (age). Epidemiologic differences in hantavirus infections between $A$. agrarius and $R$. norvegicus rats might be, in part, caused by ecologic differences, reservoir host distributions, and behavior (e.g., association with humans) (29). Seasonal circulation of SEOV infection was maintained over 1 year, suggesting 


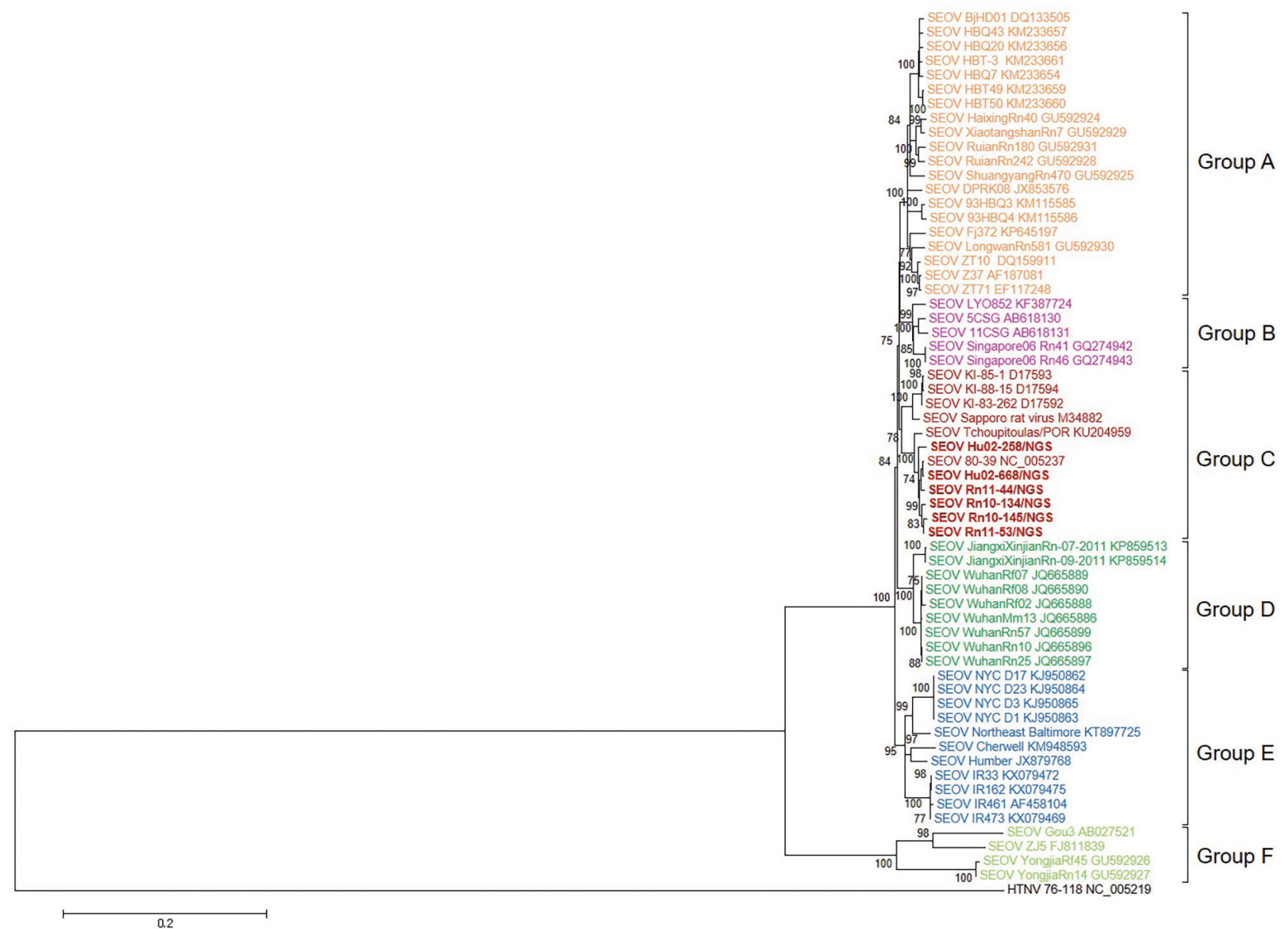

Figure 3. Phylogenetic analysis of SEOV medium RNA segments, South Korea, 2000-2016, and reference strains. A phylogenetic tree was generated by using the maximum-likelihood method with the general time reversible + gamma + invariant model of evolution and alignment of medium segment sequences (nt 47-3430) of SEOV strains. Colored groups indicate the areas where SEOV strains were identified: group A, northeastern and southeastern China and North Korea; group B, Europe (France and Belgium) and Southeast Asia (Vietnam and Singapore); group C, South Korea, Japan, and the United States; group D, southeastern China; group E, United Kingdom and the United States; group F, mountainous areas in southeastern China. Bold red indicates SEOV strains sequenced in this study. Topologies were evaluated by bootstrap analyses of 1,000 iterations. Numbers along branches are bootstrap values. GenBank accession numbers are provided. Scale bar indicates nucleotide substitutions per site. SEOV, Seoul virus.

an enzootic infectious cycle. These observations might suggest that preventive strategies for disease risk mitigation focus on limits of rat populations all year.

Our previous study demonstrated differential amounts of HTNV RNA in lung, kidney, liver, and spleen tissues of rodents collected in areas in which HFRS is prevalent (30). In addition, the genomic RNA load of MJNV, a shrewborne hantavirus, showed various patterns in different tissues in nature (28). IFA + PCR + shrews showed high and various loads of MJNV RNA in all tissues. MJNV RNA from IFA$\mathrm{PCR}+$ shrews was detected in lung but not in kidney, liver, or spleen tissues, indicating an early phase of infection before MJNV-specific IgG was produced $(31,32)$. In our study, rats Rn02-15, Rn10-134, and Rn10-145 showed various amounts of SEOV RNA in all tissues. Rat Rn11-44 had high levels of
SEOV RNA in all tissues except the liver. Virus RNA in rat Rn11-53 might reflect the early phase of SEOV infections because of highest viral load in lung tissues but not other tissues. Patterns of SEOV RNA loads might indicate systemic infections in nature and active circulation of virus among rat populations in urban HFRS-endemic areas.

Diversity of virus genomes results from genomic variation or exchanges (33). RNA viruses show high mutation rates caused by deficiencies in proofreading by virus polymerases. Genomic variation also results from a mechanism of host immune evasion $(34,35)$. Genetic exchanges, such as reassortment and recombination, lead to the generation of divergent virus progeny (36). Our previous studies identified reassortment and recombination of hantaviruses, including HTNV and MJNV, in nature $(19,28,37)$. Using nearly 
Figure 4. Phylogenetic analysis of SEOV large RNA segments, South Korea, 2000-2016, and reference strains. A phylogenetic tree was generated by using the maximum-likelihood method with the TN93 + gamma + invariant model of evolution and alignment of large segment sequences (nt 1-6510) of SEOV strains. Colored groups indicate the areas where SEOV strains were identified: group A, southeastern China and North Korea; group B, Europe (France); group C, South Korea and the United States; group E, United Kingdom and the United States. Bold red indicates SEOV strains sequenced in this study. Topologies were evaluated by bootstrap analyses of 1,000 iterations. Numbers along branches are bootstrap values. GenBank accession numbers are provided. Scale bar indicates nucleotide substitutions per site. SEOV, Seoul virus.

complete sequences of SEOV S, M, and L segments, phylogenetic analyses demonstrated that $\mathrm{S}$ segments of group $\mathrm{A}$ SEOVs formed a cluster with those of group D SEOVs and that $\mathrm{L}$ and $\mathrm{M}$ segments of group A SEOVs showed a close phylogenetic relationship with those of group B SEOVs. The S segment of group C SEOVs grouped phylogenetically with group E SEOVs. However, L and M segments of group C SEOVs formed a distant genetic cluster from those of group E SEOVs. Phylogenetic analysis of SEOV S segments showed a differential pattern from that of SEOV M segments, indicating a genome organization compatible with genetic exchanges in nature. To clarify genetic events among SEOV worldwide, whole-genome sequences of the SEOV L segment need to be investigated. Application of multiplex PCR-based NGS will be useful in elucidating phylogenetic patterns of the SEOV L segment.

In conclusion, this epidemiologic survey of $R$. norvegicus rats in urban HFRS-endemic areas of South Korea identified the prevalence and distribution of SEOV. We applied multiplex PCR-based NGS to whole-genome sequencing of SEOV tripartite RNA from retrospective serum samples from HFRS patients and rat tissues. Phylogenetic analyses demonstrated the global distribution and genetic diversity of SEOV on the basis of nearly complete genome sequences. This study provides useful information for SEOV-based surveillance, disease risk assessment, and mitigation against hantavirus outbreaks.

\section{Acknowledgments}

We thank Charles Hong for providing support; Ji Hye Kim for providing experiment support; the Pest Management staff, US
Army Garrison, Yongsan, for collecting rats; American soldiers for collecting rodents at US Army training sites/installations; and Ki-Joon Song for providing retrospective HFRS patient serum samples.

This study was supported by the Agency for Defense Development (South Korea) (grant UD160022ID), the National Research Foundation (South Korea) (grant NRF-2017M3A9E4061992) and the Armed Forces Health Surveillance Branch-Global Emerging Infections Surveillance and Response System (Silver Spring, MD, USA).

\section{About the Author}

Dr. Won-Keun Kim is a virologist and research instructor at the College of Medicine, Korea University, Seoul, South Korea. His research interests include next-generation sequencing, hantaviruses, and virus-host interactions.

\section{References}

1. Kruger DH, Figueiredo LT, Song JW, Klempa B. Hantaviruses: globally emerging pathogens. J Clin Virol. 2015;64:128-36. http://dx.doi.org/10.1016/j.jcv.2014.08.033

2. Jonsson CB, Figueiredo LT, Vapalahti O. A global perspective on hantavirus ecology, epidemiology, and disease. Clin Microbiol Rev. 2010;23:412-41. http://dx.doi.org/10.1128/CMR.00062-09

3. Jiang H, Du H, Wang LM, Wang PZ, Bai XF. Hemorrhagic fever with renal syndrome: pathogenesis and clinical picture. Front Cell Infect Microbiol. 2016;6:1.

4. Vaheri A, Strandin T, Hepojoki J, Sironen T, Henttonen H, Mäkelä S, et al. Uncovering the mysteries of hantavirus infections. Nat Rev Microbiol. 2013;11:539-50. http://dx.doi.org/10.1038/nrmicro3066

5. Lee HW, Baek LJ, Johnson KM. Isolation of Hantaan virus, the etiologic agent of Korean hemorrhagic fever, from wild urban rats. J Infect Dis. 1982;146:638-44. http://dx.doi.org/10.1093/ infdis/146.5.638 
6. Wang H, Yoshimatsu K, Ebihara H, Ogino M, Araki K, Kariwa H, et al. Genetic diversity of hantaviruses isolated in china and characterization of novel hantaviruses isolated from Niviventer confucianus and Rattus rattus. Virology. 2000;278:332-45. http://dx.doi.org/10.1006/viro.2000.0630

7. Reynes JM, Carli D, Bour JB, Boudjeltia S, Dewilde A, Gerbier G, et al. Seoul virus infection in humans, France, 2014-2016. Emerg Infect Dis. 2017;23:973-7. http://dx.doi.org/10.3201/ eid2306.160927

8. Zhang YZ, Zou Y, Fu ZF, Plyusnin A. Hantavirus infections in humans and animals, China. Emerg Infect Dis. 2010;16:1195-203. http://dx.doi.org/10.3201/eid1608.090470

9. Truong TT, Yoshimatsu K, Araki K, Lee BH, Nakamura I, Endo R, et al. Molecular epidemiological and serological studies of hantavirus infection in northern Vietnam. J Vet Med Sci. 2009;71:1357-63. http://dx.doi.org/10.1292/jvms.001357

10. Jameson LJ, Logue CH, Atkinson B, Baker N, Galbraith SE, Carroll MW, et al. The continued emergence of hantaviruses: isolation of a Seoul virus implicated in human disease, United Kingdom, October 2012. Euro Surveill. 2013;18:4-7.

11. Woods C, Palekar R, Kim P, Blythe D, de Senarclens O, Feldman K, et al. Domestically acquired seoul virus causing hemorrhagic fever with renal syndrome-Maryland, 2008. Clin Infect Dis. 2009;49:e109-12. http://dx.doi.org/10.1086/644742

12. Witkowski PT, Klempa B, Ithete NL, Auste B, Mfune JK, Hoveka J, et al. Hantaviruses in Africa. Virus Res. 2014;187:34-42. http://dx.doi.org/10.1016/j.virusres.2013.12.039

13. Kim YS, Ahn C, Han JS, Kim S, Lee JS, Lee PW. Hemorrhagic fever with renal syndrome caused by the Seoul virus. Nephron. 1995;71:419-27. http://dx.doi.org/10.1159/000188762

14. Taori SK, Jameson LJ, Campbell A, Drew PJ, McCarthy ND, Hart J, et al. UK hantavirus, renal failure, and pet rats. Lancet. 2013;381:1070. http://dx.doi.org/10.1016/S0140-6736(13)60599-1

15. Centers for Disease Control and Prevention. Multi-state outbreak of Seoul virus. March 14, 2017 [cited 2017 Nov 18]. https://www.cdc.gov/hantavirus/outbreaks/seoul-virus/

16. Fill MA, Mullins H, May AS, Henderson H, Brown SM, Chiang CF, et al. Notes from the field: multiple cases of Seoul virus infection in a household with infected pet rats-Tennessee, December 2016April 2017. MMWR Morb Mortal Wkly Rep. 2017;66:1081-2. http://dx.doi.org/10.15585/mmwr.mm6640a4

17. Firth C, Bhat M, Firth MA, Williams SH, Frye MJ, Simmonds P, et al. Detection of zoonotic pathogens and characterization of novel viruses carried by commensal Rattus norvegicus in New York City. MBio. 2014;5:e01933-14. http://dx.doi.org/10.1128/mBio.01933-14

18. Houldcroft CJ, Beale MA, Breuer J. Clinical and biological insights from viral genome sequencing. Nat Rev Microbiol. 2017;15:18392. http://dx.doi.org/10.1038/nrmicro.2016.182

19. Kim WK, Kim JA, Song DH, Lee D, Kim YC, Lee SY, et al. Phylogeographic analysis of hemorrhagic fever with renal syndrome patients using multiplex PCR-based next generation sequencing. Sci Rep. 2016;6:26017. http://dx.doi.org/10.1038/srep26017

20. Klempa B, Fichet-Calvet E, Lecompte E, Auste B, Aniskin V, Meisel H, et al. Hantavirus in African wood mouse, Guinea. Emerg Infect Dis. 2006;12:838-40. http://dx.doi.org/10.3201/ eid1205.051487

21. Li PE, Lo CC, Anderson JJ, Davenport KW, Bishop-Lilly KA, $\mathrm{Xu} \mathrm{Y}$, et al. Enabling the democratization of the genomics revolution with a fully integrated web-based bioinformatics platform. Nucleic Acids Res. 2017;45:67-80. http://dx.doi.org/ 10.1093/nar/gkw1027

22. Edgar RC. MUSCLE: multiple sequence alignment with high accuracy and high throughput. Nucleic Acids Res. 2004;32:1792-7. http://dx.doi.org/10.1093/nar/gkh340
23. Tamura K, Stecher G, Peterson D, Filipski A, Kumar S. MEGA6: Molecular Evolutionary Genetics Analysis version 6.0. Mol Biol Evol. 2013;30:2725-9. http://dx.doi.org/10.1093/molbev/mst197

24. Lin XD, Guo WP, Wang W, Zou Y, Hao ZY, Zhou DJ, et al. Migration of Norway rats resulted in the worldwide distribution of Seoul hantavirus today. J Virol. 2012;86:972-81. http://dx.doi.org/10.1128/JVI.00725-11

25. Heyman P, Plyusnina A, Berny P, Cochez C, Artois M, Zizi M, et al. Seoul hantavirus in Europe: first demonstration of the virus genome in wild Rattus norvegicus captured in France. Eur J Clin Microbiol Infect Dis. 2004;23:711-7. http://dx.doi.org/10.1007/ s10096-004-1196-3

26. Outbreak of Seoul virus in humans linked to pet rats. J Am Vet Med Assoc. 2017;250:592 [cited 2017 Nov 19]. https://www.avma.org/ News/JAVMANews/Pages/170315g.aspx

27. Klein TA, Kim HC, Chong ST, Kim JA, Lee SY, Kim WK, et al. Hantaan virus surveillance targeting small mammals at nightmare range, a high elevation military training area, Gyeonggi Province, Republic of Korea. PLoS One. 2015;10:e0118483. http://dx.doi.org/10.1371/journal.pone.0118483

28. Lee SH, Kim WK, No JS, Kim JA, Kim JI, Gu SH, et al. Dynamic circulation and genetic exchange of a shrew-borne hantavirus, Imjin virus, in the Republic of Korea. Sci Rep. 2017;7:44369. http://dx.doi.org/10.1038/srep44369

29. Zeier M, Handermann M, Bahr U, Rensch B, Müller S, Kehm R, et al. New ecological aspects of hantavirus infection: a change of a paradigm and a challenge of prevention - a review. Virus Genes. 2005;30:157-80. http://dx.doi.org/10.1007/ s11262-004-5625-2

30. No JS, Kim WK, Kim JA, Lee SH, Lee SY, Kim JH, et al. Detection of Hantaan virus RNA from anti-Hantaan virus IgG seronegative rodents in an area of high endemicity in Republic of Korea. Microbiol Immunol. 2016;60:268-71. http://dx.doi.org/ 10.1111/1348-0421.12370

31. Lee PW, Yanagihara R, Gibbs CJ Jr, Gajdusek DC. Pathogenesis of experimental Hantaan virus infection in laboratory rats. Arch Virol. 1986;88:57-66. http://dx.doi.org/10.1007/BF01310890

32. Easterbrook JD, Klein SL. Immunological mechanisms mediating hantavirus persistence in rodent reservoirs. PLoS Pathog. 2008;4:e1000172. http://dx.doi.org/10.1371/journal.ppat.1000172

33. Duffy S, Shackelton LA, Holmes EC. Rates of evolutionary change in viruses: patterns and determinants. Nat Rev Genet. 2008;9:26776. http://dx.doi.org/10.1038/nrg2323

34. Vijaykrishna D, Mukerji R, Smith GJ. RNA virus reassortment: an evolutionary mechanism for host jumps and immune evasion. PLoS Pathog. 2015;11:e1004902. http://dx.doi.org/10.1371/ journal.ppat. 1004902

35. Doud MB, Hensley SE, Bloom JD. Complete mapping of viral escape from neutralizing antibodies. PLoS Pathog. 2017;13:e1006271. http://dx.doi.org/10.1371/journal.ppat.1006271

36. McDonald SM, Nelson MI, Turner PE, Patton JT. Reassortment in segmented RNA viruses: mechanisms and outcomes. Nat Rev Microbiol. 2016;14:448-60. http://dx.doi.org/10.1038/ nrmicro.2016.46

37. Kim JA, Kim WK, No JS, Lee SH, Lee SY, Kim JH, et al. Genetic diversity and reassortment of Hantaan virus tripartite RNA genomes in nature, the Republic of Korea. PLoS Neg1 Trop Dis. 2016;10:e0004650. http://dx.doi.org/10.1371/ journal.pntd. 0004650

Address for correspondence: Jin-Won Song, Department of Microbiology, Korea University School of Medicine, Inchon-ro 73, Seongbuk-gu, Seoul 02841, South Korea; email: jwsong@korea.ac.kr 